\title{
Applicability of Item Mapping in Rating the Severity of Pathological Personality Traits
}

\author{
Lucas de Francisco Carvalho*, Jonatha Tiago Bacciotti, Catarina Possenti Sette, \\ \& Ana Maria Reis \\ Universidade São Francisco, Bragança Paulista, SP, Brasil
}

\begin{abstract}
The aim of this study was to investigate the combined use of two pathological personality tests, the Dimensional Clinical Personality Inventory (IDCP) and the Personality Inventory for DSM-5 (PID-5), within the context of incremental validity in order to verify the increasing severity of the constructs used. We generated item maps for sets of items based on three dimensions of IDCP and five facets of PID-5, selected according to the possibility of pairing between scales. The study included 642 individuals, predominantly women aged over 18, divided into three groups according to the dimensions and facets. There was an increase in the level of severity, typically related to the different personality disorders, in addition to the complementation between instruments, providing incremental validity. The use of item mapping helped us understand the increasing severity of the traits, and allowed the verification of the clinical relevance of the constructs.
\end{abstract}

KEYWORDS: personality disorders, personality traits, psychiatric disorders

\section{Aplicação do mapa de itens para investigação da severidade de características patológicas da personalidade}

\begin{abstract}
RESUMO - O objetivo deste estudo foi investigar o uso conjunto de dois instrumentos que avaliam características patológicas da personalidade, o Inventário Dimensional Clínico da Personalidade (IDCP) e o Personality Inventory for DSM-5 (PID-5), dentro do paradigma da validade incremental, bem como verificar a evolução da severidade dos construtos utilizados. Foram gerados mapas de itens para conjuntos de itens com base em três dimensões do IDCP e cinco facetas do PID-5, selecionados de acordo com a possibilidade de pareamento entre escalas dos instrumentos. Participaram do estudo 642 indivíduos, predominantemente mulheres, com idade igual ou superior a 18 anos, divididos em três grupos de acordo com as dimensões e facetas respondidas. Observou-se um aumento no nível de severidade patológica, tipicamente relacionado a transtornos da personalidade distintos, além da complementação entre os instrumentos, conferindo validade incremental. A aplicação dos mapas de itens auxiliou na compreensão do aumento da severidade dos traços e possibilitou a verificação da relevância clínica dos construtos.
\end{abstract}

PALAVRAS-CHAVE: transtornos da personalidade, traços de personalidade, transtornos psiquiátricos

Personality disorders are among the most frequently treated conditions in clinical practice, as indicated by the existing literature (American Psychiatric Association [APA], 2013; Paris, 2015; Zuccolo, Corhs, \& Savoia, 2013). However, in Brazil, studies focusing on the assessment of personality disorders are scarce, as are the number of instruments available in the national context for the assessment of common characteristics of these disorders (Carvalho, Bartholomeu, \& Silva, 2010).
Among the tools available for personality assessment in Brazil, there are two instruments that assess characteristics of personality disorders, namely the Inventário Dimensional Clínico da Personalidade (Dimensional Clinical Personality Inventory; IDCP), developed in Brazil by Carvalho and Primi (2015) and the Personality Inventory for DSM-5 (PID5), developed in the United States by Krueger, Derringer, Markon, Watson, and Skodol (2012). Both

*Email: lucas@labape.com.br 
were developed for clinical application and are self-report instruments.

The IDCP is a self-report test for the assessment of pathological personality traits, which can be configured as personality disorders, based on Theodore Millon's theory and on the Axis II section of the fourth edition of the Diagnostic and Statistical Manual of Mental Disorders (DSM-IV-TR; APA, 2003). Specifically, the typical traits of each personality disorder according to Millon's theory were used as basis for the development of IDCP; in addition, the diagnostic criteria from the personality disorders were also used as groundwork. The IDCP is supported in the dimensional perspective, and consists of 163 items, grouped into 12 dimensions (Dependence, Aggressiveness, Mood Instability, Eccentricity, Attention Seeking, Distrust, Grandiosity, Isolation, Criticism Avoidance, Self-Sacrifice, Conscientiousness, and Impulsivity) that should be answered through a 4-point Likert-type scale, being 1 for "nothing - it has nothing to do with me", 2 for "little - it has little to do with me," 3 for "moderately - it has something do with me" and 4 for "much - it has much to do with me" (Carvalho \& Primi, 2015). Studies show the adequacy of the IDCP from the psychometric perspective (Carvalho \& Primi, 2015; Carvalho \& Primi, 2016; Carvalho, Primi, \& Stone, 2014).

The translated and adapted version of the Personality Inventory for DSM-5 (PID-5; Krueger, Derringer, Markon, Watson, \& Skodol, 2012), in turn, is a self-report instrument whose goal is the assessment of the 25 facets of maladaptive personality traits described in section III of the DSM-5 which can be organized into five domains: Antagonism, Detachment, Disinhibition, Negative Affectivity, and Psychoticism. It is comprised of 220 items with Likert-type responses ranging from 0 for "very false or often false", 1 for "sometimes or somewhat false", 2 for "sometimes or somewhat true", and 3 for "very true or often true". There were no national studies verifying the psychometric properties of the Brazilian version of the instrument, but several studies (Al-Dajani, Gralnick, \& Baby, 2016; Anderson et al., 2013; Anderson et al., 2015; Krueger et al., 2012; Thomas et al., 2013; Anderson et al.,
2015) presented data indicating the psychometric adequacy of the original test.

It is noteworthy that although these are tests that assess the same construct (i.e., pathological personality traits) the instruments present different structures; while the IDCP consists of 12 dimensions, the PID-5 has 25 facets. Moreover, the theoretical basis for IDCP is Millon and the DSM-IV-TR, while for PID-5, the basis is the 25 traits from the section III of the DSM-5. Table 1, which is based on Carvalho and Primi (2015) and Krueger et al., (2012), shows that the dimensions of the IDCP and the PID-5 facets can be arranged according to their correspondences.

Table 1 consists of two columns; the first presents the dimensions of the IDCP (Carvalho \& Primi, 2015) and the second shows the PID-5 facets (Krueger et al., 2012). They are presented according to the theoretical relationship between dimensions and facets, considering their definitions. It can be observed that the number of facets related to the IDCP dimensions varied from one to four, and only the Grandiosity dimension presented just one associated facet. Mood Instability and Eccentricity presented four facets in association. In addition, one PID-5 facet was not allocated in any dimension of the IDCP, namely Deceitfulness, since these characteristics were not represented in the dimensions of the IDCP.

Another important aspect that should be emphasized is the fact that the instruments can be regarded as complementary in the assessment of personality disorders. For instance, the Grandiosity dimension in the IDCP, which refers to the pleasure associated with acknowledgement by others and with the extreme need for admiration by others, as demonstrated by the item "People do not understand me and do not give me the value I deserve"; and the Grandiosity facet of PID-5 is better represented by the beliefs of entitlement and superiority, e.g. "To be honest, I'm simply more important than the others." Although both refer to the same underlying construct, i.e., considering oneself as superior to others, which is typical of narcissistic functioning (APA, 2013), the focus of the items as well as the severity seem to change from an instrument to another. However, to

Table 1. Dimensions on the IDCP and corresponding facets on the PID5

\begin{tabular}{cc}
\hline IDCP & PID-5 \\
\hline Dependence & Separation Insecurity and Submission \\
Aggressiveness & Callousness and Hostility \\
Mood Instability & Anxiousness, Emotional Lability, Impulsivity, and Depressivity \\
Eccentricity & Eccentricity, Perceptual Dysregulation, Unusual Beliefs, and Experiences \\
Attention Seeking & Attention Seeking and Manipulativeness \\
Distrust & Suspiciousness and Withdrawal \\
Grandiosity & Grandiosity \\
Isolation & Anhedonia, Depressivity, and Withdrawal \\
Criticism Avoidance & Intimacy Avoidance and Withdrawal \\
Self-Sacrifice & Depressivity and Submission \\
Conscientiousness & Perseveration and Rigid Perfectionism \\
Impulsivity & Irresponsibility, Impulsivity, and Risk-taking \\
\hline
\end{tabular}


date, no research has verified the results of the simultaneous administration of these two instruments.

The ability of distinct instruments to complement each other in the assessment of a particular construct in a given context is known as incremental validity, which is based on statistical procedures to verify whether a particular measure has explanatory power over and beyond the other measure to predict a relevant criterion (Hunsley \& Meyer, 2003; Meyer, 1999; Pasquali, 2007). Typically, the incremental validity for an assessment measurement may be verified by applying the hierarchical regression analysis. However, an unusual way to check this modality of evidence, as well as for understanding the development of constructs, would be the use of item mapping (Linacre, 2009) for interpretation referenced on the test items. With this procedure, it is possible to study how the severity of traits increase, and it is also possible to investigate if there is an increase by a specific set of items in relation to another set of items (Embretson \& Reise, 2000). The use of item mapping for understanding the construct has been used before in previous studies (Carvalho, Primi, \& Meyer, 2012; Primi, Carvalho, Miguel, \& Muniz, 2010), but not on the paradigm of incremental validity. The aim of this study is to investigate the combined use of the IDCP and the PID-5, within the context of incremental validity, in order to observe the increasing severity of the traits used. Therefore, according to the theoretical possibility of pairing between scales, we generated item maps for groups of items based on three dimensions of IDCP and five facets of PID-5.

\section{METHOD}

\section{Participants}

There were 642 participants in this study, wherein 199 answered measures related to the dependence trait (i.e., group 1); 230 answered measures related to the distrust trait (i.e., group 2); and 213 answered measures related to the isolation trait (i.e., group 3). Group 1 consisted of 199 individuals, aged between 18 and $54(\mathrm{M}=26.37, \mathrm{SD}=8.13)$, $71.4 \%$ of which were women, most with incomplete higher education $(51.8 \%)$, followed by incomplete secondary education $(20.6 \%)$. In addition, $10 \%$ reported to had undergone psychiatric treatment, $4.5 \%$ had used some psychotropic medication, and $31.2 \%$ had been through psychotherapy. Group 2, related to the Distrust dimension, was represented by 230 people, aged between 18 and 63 $(\mathrm{M}=23, \mathrm{SD}=9.44)$, in which $76.4 \%$ were women, mostly university students $(52.6 \%)$, followed by individuals with a higher education degree (17.8\%). Among them, $9.5 \%$ had undergone psychiatric treatment, $2.2 \%$ had used psychotropic medication, and $41.3 \%$ had been through psychotherapy. Finally, the third group (Isolation dimension), was composed of 213 individuals, aged between 18 and $69(\mathrm{M}=25.56, \mathrm{SD}=8.70)$, mostly women $(74.3 \%)$ and university students $(83.6 \%)$; in this group, $7.5 \%$ reported having undergone psychiatric treatment, $5.1 \%$, the use of psychotropic medication, and $23.4 \%$, psychotherapy.

\section{Instruments}

As it is known, the Dimensional Clinical Personality Inventory ([IDCP]; Carvalho \& Primi, 2015) was developed based on diagnostic criteria presented by Millon (2011) and on Axis II of the DSM-IV-TR (APA, 2003), for the evaluation of pathological personality traits. It is a self-report instrument, comprised of 163 items and 12 dimensions, and studies have demonstrated the adequacy of its psychometric properties (Carvalho \& Primi, 2015, 2016). The dimensions are: Dependency (20 items), Aggressiveness (27 items), Mood Instability (27 items), Eccentricity (20 items), Need for Attention (16 items), Distrust (13 items), Grandiosity (12 items), Isolation (11 items), Criticism Avoidance (7 items), Self-sacrifice (7 items), Conscientiousness (11 items) and Inconsequence (5 items).

Similarly, the Personality Inventory for DSM-5 (PID-5.; Krueger et al, 2012) was also developed for the assessment pathological personality traits; however, it was based on the DSM-5 (APA, 2013). It is a self-report test with 225 items divided into 25 distinct facets (Anhedonia, Anxiousness, Attention Seeking, Callousness, Deceitfulness, Depressiveness, Distractibility, Eccentricity, Emotional Lability, Grandiosity, Hostility, Impulsivity, Intimacy Avoidance, Irresponsibility, Manipulativeness, Perceptual Dysregulation, Perseveration, Restricted Affectivity, Rigid Perfectionism, Risk Taking, Separation Insecurity, Submissiveness, Suspiciousness, Unusual Beliefs and Experiences, and Withdrawal). The literature around the world shows adequacy of the psychometric properties of the PID-5 in college students, general population and psychiatric patients (Al-Dajani, Gralnick and Baby, 2016; Anderson et al., 2013; Anderson et al., 2015; Krueger et al., 2012; Thomas et al., 2013; Anderson et al., 2015). In Brazil, the translation and adaptation of the test by Oliveira (2016) showed adequacy in relation to the psychometric properties (Oliveira \& Krueger, 2015).

\section{Procedures}

This research was approved by a Committee of Ethics in Research. People were recruited from the community on social media, and the tests were administered online. Participants received detailed information concerning the 
goals of the study and signed an informed consent form prior to the data collection procedures.

To meet the goals of the present study, we adopted a procedure outlined in five steps. Afterwards, through the rating scale model, the methodology used was based on the following steps: (a) establishment of the IDCP dimensions and the PID-5 facets that should be grouped, independently and afterwards, by consensus of the authors of the current study, as shown in Table 1; (b) verification of the dimensionality (Tavakol \& Dennick, 2011) of the sets of items (IDCP + PID-5) established by Cronbach's alpha $(\geq 0.70$; Nunnally, 1978; Tavakol \& Dennick, 2011) and eigenvalue of the first factor of these groups of items (first factor at least four times greater than the second; Morizot, Ainsworth, \& Reise, 2007; Hattie, 1985); (c) calibration of the parameters of the items contained in the groups of dimensions (IDCP) and facets (PID-5) determined via rating scale model and carried out in the Winsteps software; (d) analysis of item maps to define the interpretations in relation to the items based on the Carvalho, Meyer, and Primi (2012), and Primi et al (2010) approach. Regarding the dimensionality verification, we sought to find a predominance of unidimensionality, considering that the dimensions from IDCP and the facets from PID-5 are similar, but not the same, and the predominance of unidimensionality is enough for the analysis (Linacre, 1991). It is important to note that for item parameter calibration the average difficulty (b) was set at zero.
Considering the established criteria, several groupings between IDCP dimensions and PID-5 facets were tested, always based on the constructs in evaluation; i.e., possibilities of grouping items were observed in both tests, starting from the theoretical coherence (e.g., Dependence with Separation Insecurity; Mood Instability with Emotional Lability, Aggressiveness with Hostility, among others), using as a basis the sets of diagnostic criteria for personality disorders presented in sections II and III of the DSM-5 (APA, 2013). Therefore, the following dimensions of the IDCP were tested: Dependence, Aggressiveness, Mood Instability, Distrust, Isolation, Criticism Avoidance, and Self-Sacrifice. Other dimensions were not tested as they were not used in the data collection. The grouping possibilities with PID-5 facets were performed such as presented in Table 1.

Finally, having established the groupings, we sought to investigate the incremental capacity among the items of the two instruments, as well as to understand the evolution in terms of severity of the constructs in each group, based on the items of the IDCP and the PID-5. Therefore, item maps were generated by the Winsteps software, based on one of the mathematical models of Item Response Theory, based on the rating scale model. Each one of the maps was qualitatively analyzed within two criteria (Carvalho, Meyer \& Primi, 2012; Primi et al, 2010): (a) difference of at least .5 logits between the thresholds of categories 3 and 4 (i.e., the categories closer to endorsement of the item), establishing a cutoff between items, and (b) the content of the items.

\section{RESULTS}

Based on pre-established criteria, three of the enclosed correspondences were selected. They were selected according to the content and the pairing possibility of PID-5 facets; moreover, we chose only cases in which unidimensionality predominance could be found. It is noteworthy that in all cases the first factor found for the sets of items was at least four times greater than the second factor in terms of eigenvalues and we found $\alpha \geq 0.80$. The groupings were: Isolation (IDCP) with Depressivity and Intimacy Avoidance (PID-5); Dependence (IDCP) with Separation Insecurity and Submission (PID-5); and Distrust (IDCP) with Suspiciousness and Intimacy Avoidance (PID-5). Subsequently, based on the difference of at least .5 logits and the content of the instruments items in Table 2 and Figure 1, we can observe the results regarding the convergence of the Isolation dimension (ISCP) with the Depressivity and Intimacy Avoidance facets of PID-5.

This first grouping refers to the tendency for isolation with a tendency to lowered mood, anhedonia, and selfdepreciation beliefs. We observed that the first two groups of items have no clinical relevance, i.e., the correlation of these items should not express concern from the clinical point of view, according to the content of the items. In turn, the other three groups of items show content that should be taken into consideration by the professional in a clinical setting. We also observed a discrepancy in the number of IDCP and PID-5 items by established grouping, i.e., in some cases the number of items on one scale is expressively higher than on the other. Also, the last column shows what each group of items refers to primarily.

Group 1 includes items about the tendency towards isolation; group 2, in addition to expressing a tendency towards isolation, also refers to irritability; in group 3, isolation is more pronounced including intimacy avoidance, depressiveness, and also negative self; in group 4 there is an increase in the severity of characteristics related to intimacy avoidance, more general characteristics of depressiveness, and again a tendency towards a negative approach to oneself; the last group is represented by life-threatening suicidal ideation.

The map of items presents percentiles, means, and standard deviation, and distribution of participants at the bottom. It can be observed that most of the subjects rested on a low theta range (i.e., level at the latent construct), predominantly negative. In the central area, there are response categories $1-4$, and the appropriate thresholds 
Falta chamada da tabela 2

Table 2. Convergence of the dimensions Isolation (IDCP) and facets Depressivity and Intimacy Avoidance (PID-5)

\begin{tabular}{ccccc}
\hline Groups & IDCP Items & PID-5 Items & Clinical Relevance & Functioning \\
\hline 1 & 1 & 1 & No clinical relevance & Mild isolation \\
2 & 2 & 0 & No clinical relevance & Irritability \\
3 & 6 & 5 & Clinically relevant & Pronounced isolation with avoidance and negative self \\
& 2 & 16 & Clinically relevant & Pronounced isolation with avoidance, depressiveness \\
4 & 0 & 2 & Clinically relevant & Suicidal ideation \\
5
\end{tabular}

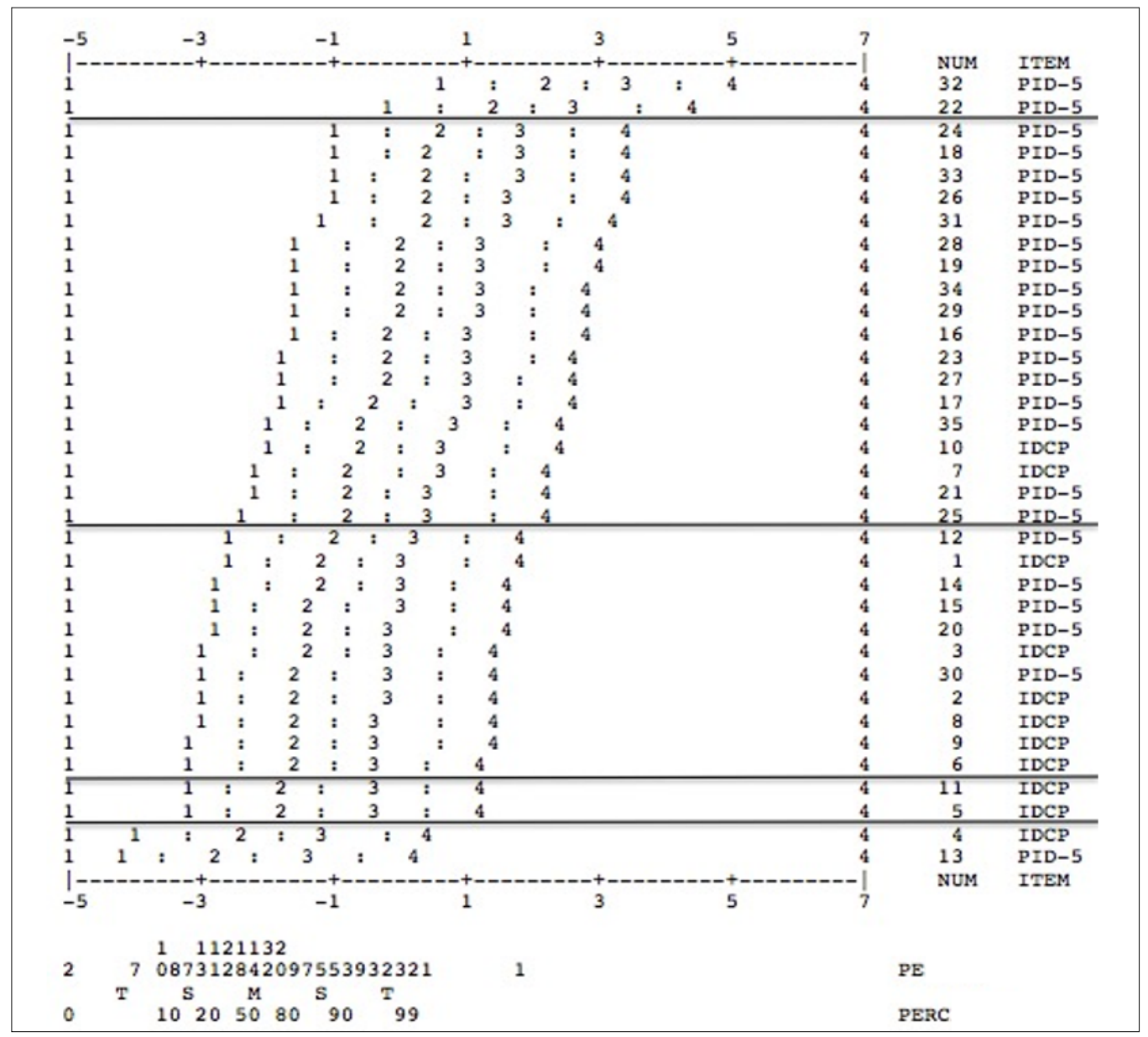

Figure 1. Map of grouping items with the Isolation dimension on the IDCP. Note. $P E=$ Person; PERC $=$ Percentile.

represented by ":". We can observe a tendency of the categories towards the right, suggesting that as high as the participants got in the latent construct (i.e., pathological levels), the items are still less endorsed. In both columns, there is the number of IDCP and PID-5 items and to which instrument the item belongs. Finally, the horizontal lines crossing the map represent the groups of items explained in Table 2. Table 3 and Figure 2 present the results found in the correspondence between the Dependence dimension and the facets Separation Insecurity and Submission.

The grouping corresponding to the Dependence dimension was composed of six sets of items, and only the first did not present clinical relevance. Once again it is possible to observe a discrepancy in the number of items of each instrument in the categories; for instance, in category 4 the number of IDCP items is higher than the number of PID-5 items, but in category 6 there is one PID-5 item and no IDCP item.

In the groups of items, the first one is related to dependence on others in a milder and broader way. Group 2 is clinically relevant, and the dependence construct is more specific (than the dependence observed in group 1) and related to the need for others for concluding activities, i.e., the person needs the other to help with decisions, and needs to have people around them, providing support. Group 3 presents as its core functioning the need to have the other, 
Table 3. Convergence of Dependence dimension (IDCP) and Separation Insecurity and Submission facets (PID-5)

\begin{tabular}{ccccc}
\hline Groups & IDCP Items & PID-5 Items & Clinical Relevance & Functioning \\
\hline 1 & 1 & 0 & No clinical relevance & Generic dependence \\
2 & 3 & 0 & Clinically relevant & $\begin{array}{c}\text { Specific Dependence related to the need for others with the } \\
\text { completion of activities and behaviors to have the other } \\
3\end{array}$ \\
3 & 11 & 3 & Clinically relevant & $\begin{array}{c}\text { Need for others, feeling of inadequacy, and pessimism } \\
\text { Fear of abandonment, feelings of inadequacy, dependence } \\
\text { with negative self-view }\end{array}$ \\
5 & 2 & 3 & Clinically relevant & $\begin{array}{c}\text { Fear of abandonment, submission, and difficulties in } \\
\text { decision-making }\end{array}$ \\
6 & 0 & 4 & Clinically relevant & Intense abandonment fears with acceptance of losses
\end{tabular}

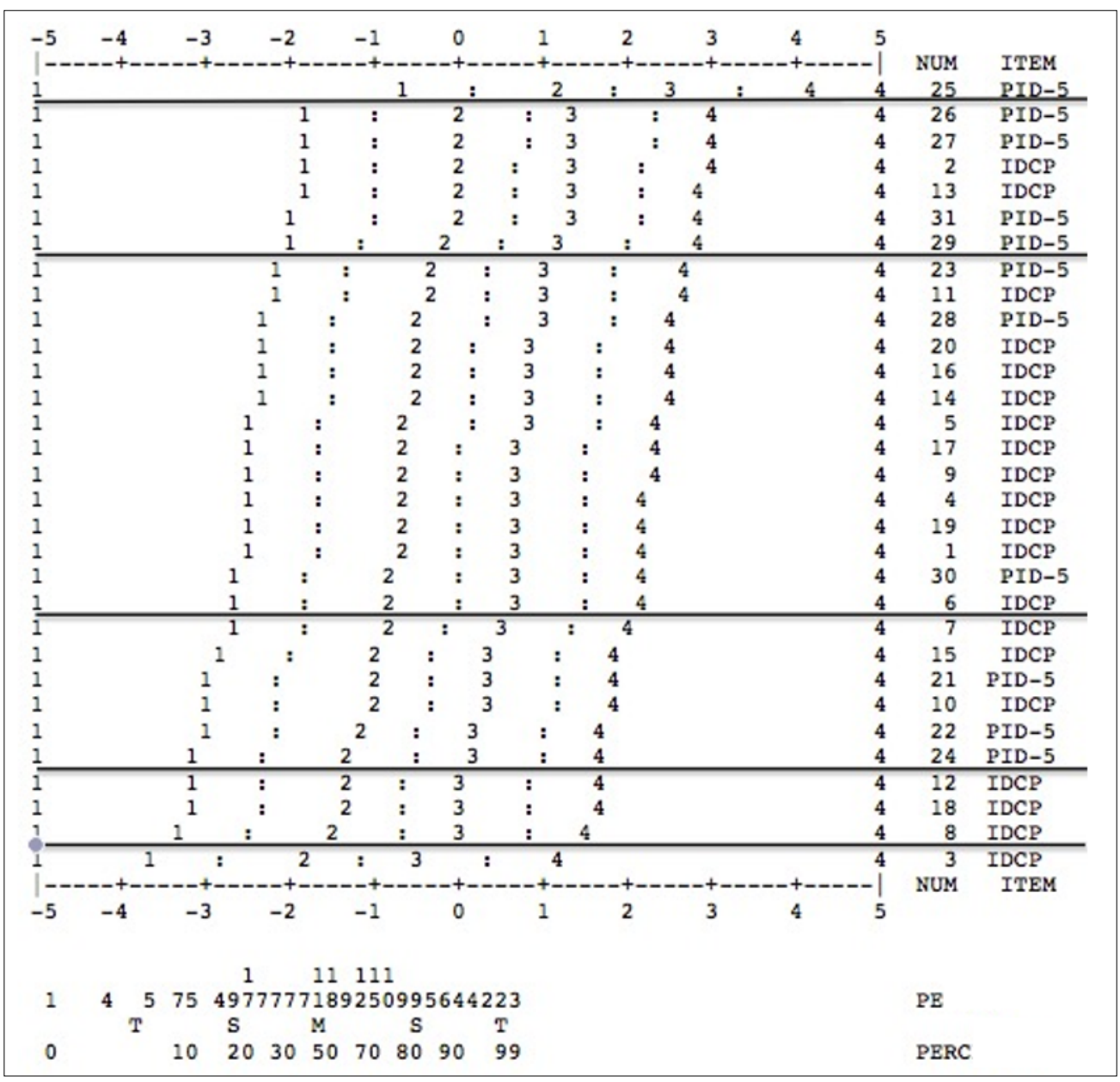

Figure 2. Map of grouping items with the Dependence dimension on the IDCP

Note. $P E=$ Person; PERC $=$ Percentile.

with the presence of feelings of inadequacy and pessimism. Group 4 is related to fear of abandonment, feelings of inadequacy, and dependence appears with a negative selfview (negative self). The penultimate group presents as main features fear of abandonment, submission, and decisionmaking difficulties. Finally, group 6 is characterized by a growing fear of abandonment, and the tendency to accept personal losses while trying to help others.

The aforementioned information can be seen in Figure 2, which confirms the tendency of items to be less endorsed as they reach more severe levels in the construct (i.e., higher levels), which in this case is the inability to perform relevant decision-making and the tendency towards need for emotional and physical support of those surrounding oneself. Then, as a last grouping, Table 4 and Figure 3 show the categories resulting from the convergence of Distrust (IDCP) with Suspiciousness and Intimacy Avoidance (PID-5).

It can be observed that among the five groups, only group 1 showed no relevance clinically. Also, as we have already seen in previous groupings, the discrepancy between the 
Table 4.Convergence of the Distrust dimension (IDCP) and the Suspiciousness and Intimacy Avoidance facets (PID-5)

\begin{tabular}{cccccc}
\hline Groups & IDCP Items & PID-5 Items & Clinical Relevance & Functioning & Generic distrust \\
1 & 1 & 3 & No clinical relevance & Clinically relevant & Implicit and defensive distrust \\
3 & 4 & 0 & Clinically relevant & Explicit distrust and persecutory \\
beliefs with losses & Clinically relevant & More evident explicit distrust, persecutory \\
beliefs, and avoidance with losses & 3 & Clinically relevant & Intense avoidance \\
5 & 2 & 6 & &
\end{tabular}

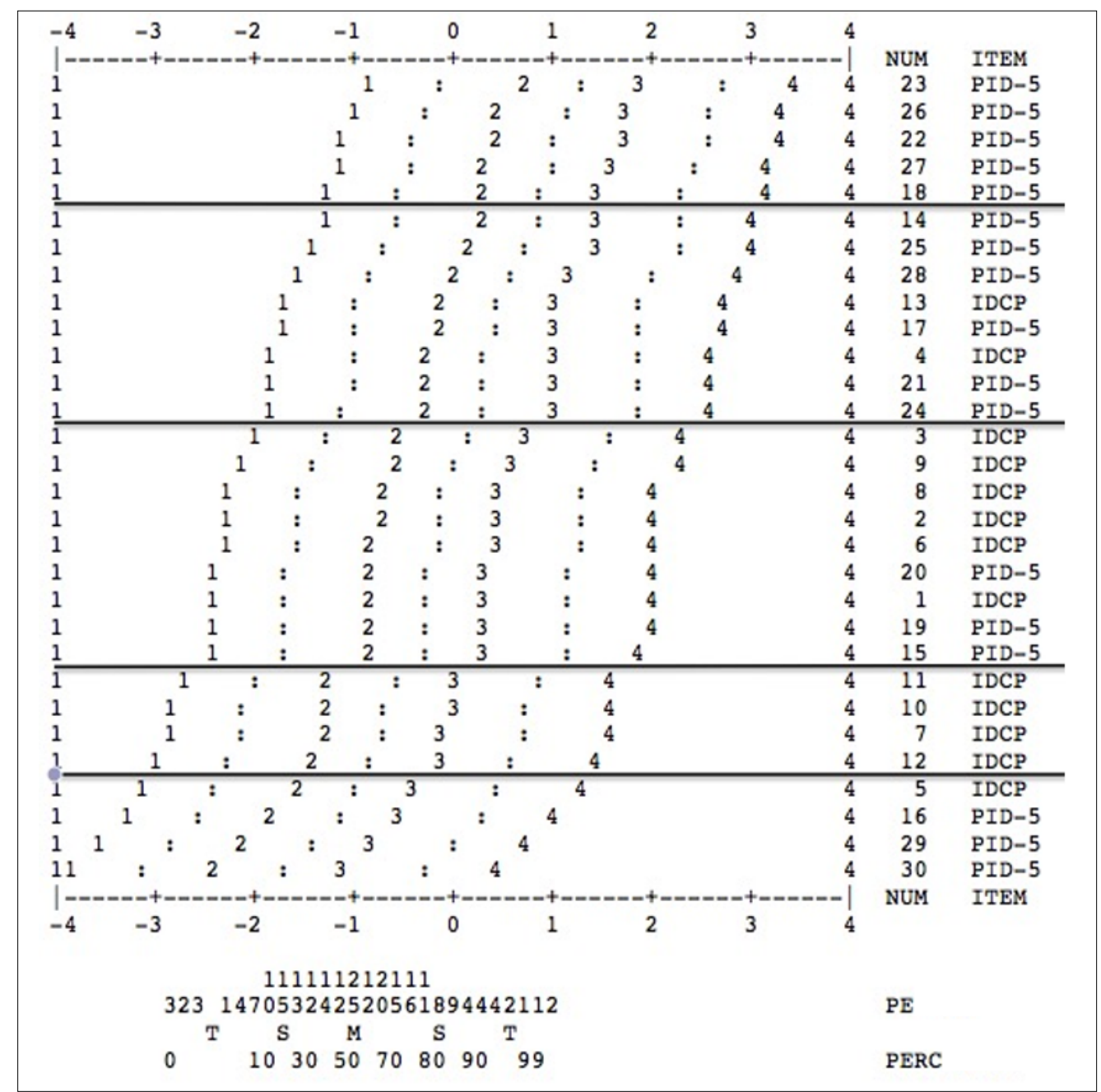

Figure 3. Map of grouping items with the Distrust dimension on the IDCP Note. $P E=$ Person; PERC $=$ Percentile.

number of IDCP and PID-5 items is evident throughout the categories, so that some categories do not present any item of either instrument. Group 1 relates to milder and broader behaviors of distrust, not very specifically; in contrast, in group 2 distrust is more implicit and occurs in a defensive manner; in the set of items in group 3 distrust becomes explicit and there is the presence of persecutory beliefs with evident harm to the individual; in the next group, the behaviors of distrust become even more explicit, with the presence of persecutory beliefs and avoidance with losses to the subject; and in group 5, the central functioning is a more evident presence of avoidant behaviors, refusing to interact with people for fear of being harmed by them.

The map of items of this set of variables, that is interacting with people to a tendency of not trusting people, believing that they will be harmed by them, presents a clear drop towards the right by the categories of items, aside from people being mainly represented in the negative theta ranges, such as in the previous cases. 


\section{DISCUSSION}

In the present study the rating scale model was used as an alternative to assist in the understanding of clinically relevant constructs: tendency for isolation or social apathy, difficulty in decision-making without the assistance of others and constant need for social support, and the inability to trust others with the belief that others are out to hurt them. Furthermore, we showed the application of the item map based on the mathematical model employed, since groups of items from two different instruments were applied in the tests.

It can be observed that the established groupings (Isolation, Dependence, and Distrust) are related to pathological functioning present in the pertaining literature (APA, 2003; APA, 2013; Millon, 2011; Skodol et al., 2011). The Isolation grouping refers to a tendency toward being alone, irritability when forced to be among others, general difficulty in establishing intimacy, including low mood, negative view of oneself, and even suicidal ideation in more severe cases of isolation. These trends are typical of pathological functioning of personality; more typically observed in people diagnosed with schizoid, schizotypal, and avoidant personality disorders (APA, 2013).

The second group, Dependence, relates to an important need to have the support and advice of people while making important decisions, besides an emotional dependency on others. Such pattern may include feelings of inadequacy about oneself, with evident fear of abandonment, even accepting personal losses in favor of others, as to not lose support. Typically, a personality functioning that is underlying to borderline and dependent personality disorders is related to these characteristics.

In the last group, Distrust, we observed a significant difficulty in trusting others, beliefs that others will harm oneself, persecutory beliefs that lead to losses, and avoidant behaviors, showing fear of interacting with people. In this case, the most related disorders are the paranoid and the avoidant personality disorders.

It is important to note that the diagnostic criteria for personality disorders in DSM-IV and DSM-5 (APA, 2003; APA, 2013) did not receive different degrees of clinical relevance or loss to the individual. Accordingly, within the categorical perspective, a person is diagnosed with a personality disorder when meeting a minimum number of criteria, regardless of the criteria within a specific diagnostic category (e.g., borderline personality disorder). The data presented here help in further understanding the relationship between behaviors that are representative of the diagnostic criteria. Moreover, it helps to understand the diagnostic criteria under the dimensional perspective.

In the Isolation grouping, it was observed that when someone presents a more dysfunctional functioning, or higher levels in the latent construct (theta), avoidant features are more evident, such as the difficulty in establishing intimacy with others and a negative view of oneself. In even more extreme levels, with increasing self-devaluation, these people also report suicidal ideation. In the Dependence grouping, it starts with a milder functioning where the individual reports the need for others in decision-making scenarios, up to levels where the fear of abandonment is evident along with submissive behaviors and feelings of inadequacy. Regarding the Distrust grouping, milder functioning indicates less explicit difficulties of relying on others and is aimed at protecting themselves against possible harms, which in more extreme levels becomes more explicit, with persecutory beliefs and evident avoidance of others. In all three cases there are losses in interpersonal relationships and also in their self-view in the most extreme levels, which supports the current understanding of the latent function of personality disorders (Skodol et al., 2011).

On the one hand, the IDCP and the PID-5 are selfreported instruments that allow the identification of personality profiles within 12 dimensions and 25 facets (Carvalho \& Primi, 2015; Krueger et al, 2012), focusing on pathological traits, but that do not allow the establishment of diagnosis of personality disorders. On the other hand, despite the impossibility of a diagnosis, the results of this study are relevant as they demonstrate from which moment, or rather, from the agreement about which items the clinician should be concerned in relation to the constructs currently investigated when assessed by these instruments. In all cases, there was at least one grouping of items whose clinical relevance was not present, that is, whose agreement by respondents should not concern the professional in the clinical context. This logic pertains to the dimensional perspective, and future studies could test the possibility of establishing cutoffs from the use of item maps. As we could find different item groups according to severity, maybe the more severe groups could be used as indicators of pathology. Empirical studies including people diagnosed with personality disorders are needed in order to confirm this hypothesis.

We may notice, in all three cases, two important characteristics, namely: the increasing severity of the functioning underlying the grouping of items, and the incremental capacity among the items of the instruments used. Regarding the first feature, it is noteworthy that both the IDCP and the PID-5 were developed in a dimensional perspective (Carvalho \& Primi, 2015; Krueger et al, 2012.), implying that the extremes are harmful. However, both tests were conducted to evaluate the pathological range at extreme levels of the analyzed constructs, represented by their dimensions and facets. Therefore, low scores on these instruments are hard to interpret. It is significant, on the map of items, that people with low marks, or with low levels of theta, tend not to agree with any items or to agree with very few and, in contrast, subjects with high theta levels (i.e., people low in the latent construct) tend to endorse the 
items, showing severe functioning in terms of personality pathology.

Taking the Dependent group as an example, a person with theta around -1 tends to agree only with the related items in group 1; differently, a person with theta around zero tends to agree with the items of the groupings 1 to 4 . From a clinical point of view, this difference, expressed by 1 logit on the map, is extremely important (see Linacre, 2009; Elliot et al., 2006), and in the first case, the use of both IDCP and PID-5 for the tendency towards need for others does not provide information that should be clinically considered. In the second case, in turn, the person demonstrates great difficulty in decision-making without the support of others, with fear of abandonment. In this case, the clinician should work with the patient towards interventions that tackle these characteristics. Thus the practical use of item mapping in the clinical setting is demonstrated.
Moreover, as a second important characteristic to be considered, the distribution of items over the maps (some categories were represented by items only in the IDCP or the PID-5) shows the importance of the combined application of dimensions and facets of these instruments for thorough understanding of the patient's functioning and of the most likely behaviors according to the level of theta. Based on that, we can understand that incremental validity evidences were observed, with the ability of the items to help in the evaluative understanding of a given construct having now been verified (Hunsley \& Meyer, 2003; Meyer, 1999; Pasquali, 2007). Therefore, based on the data presented, there are indicators that can rely on evidence of incremental validity of the instruments used, considering the groupings of dimensions and facets. However, empirical studies with clinical groups (e.g., patients with personality disorders) should be conducted in order to test the combined use of the instruments.

\section{FINAL CONSIDERATIONS}

We consider the goals of this study met, with the understanding of the evolution of symptomatic severity of the constructs, and with the verification of severity increase considering both the IDCP and PID-5 at the same time. As for the limitations of this study, we can mention the use of primarily non-clinical samples and the predominance of women subjects, as well as the presentation of some groupings (both because of the space for publication and the criteria used). Further studies should seek to replicate the procedures currently used with other groupings of items and also with the use of other instruments of clinical relevance.

\section{REFERENCES}

Al-Dajani, N., Gralnick, T. M., \& Bagby, R. M. (2016). A psychometric review of the Personality Inventory for DSM-5 (PID-5): Current status and future directions. Journal of Personality Assessment, 98(1), 62-81. doi: 10.1080/00223891.2015.1107572

Anderson, J. L., Sellbom, M., Bagby, R. M., Quilty, L. C., Veltri, C. O. C., Markon, K. E., \& Krueger, R. F. (2013). On the convergence between PSY-5 domains and PID-5 domains and facets: implications for assessment of DSM-5 personality traits. Assessment, 20(3), 286-294. doi: 10.1177/1073191112471141

Anderson, J. L., Sellbom, M., Ayearst, M., Quilty, L. C., Chmielewski, M., \& Bagby, R. M. (2015). Associations Between DSM-5 Section III Personality Traits and the Minnesota Multiphasic Personality Inventory 2-Restructured Form (MMPI-2RF) Scales in a Psychiatric Patient Sample. Psychological Assessment, 27(3), 801-815. doi: 10.1037/ pas0000096

American Psychiatric Association. (2003). Manual Diagnóstico e Estatístico de Transtornos Mentais - DSM-IV-TR (4⿳a ed.). Porto Alegre: Artmed.

American Psychiatric Association. (2013). Diagnostic and Statistical Manual of Mental Disorders (5th Edition). Washington.

Carvalho, L. F., Bartholomeu, D., \& Silva, M. C. R. (2010). Instrumentos para Avaliação dos Transtornos da Personalidade no Brasil. Avaliação Psicológica, 9(2), 289-298. Retrieved from http://pepsic.bvsalud.org/scielo.php?script=sci_arttext \&pid=S1677-04712010000200013

Carvalho, L. F., \& Primi, R. (2015). Development and internal structure investigation of the Dimensional Clinical Personality
Inventory (IDCP). Psicologia: Reflexão e Crítica, 28(2), 213221. doi: $10.1590 / 1678-7153.201528212$

Carvalho, L. F., \& Primi, R. (2016). Prototype Matching of Personality Disorders with the Dimensional Clinical Personality Inventory. Psicologia: Teoria e Pesquisa, 32(2), 1-9. doi:10.1590/0102-3772e322214

Carvalho, L. F., Primi, R., \& Meyer, G. J. (2012). Application of the rasch model in measuring personality disorders. Trends in Psychiatry and Psychotherapy, 34(2), 101-109. doi: 10.1590/ S2237-60892012000200009

Carvalho, L. F., Primi, R., \& Stone, G. E. (2014). Psychometric Properties of the Inventário Dimensional Clínico da Personalidade (IDCP) using the Rating Scale Model. Avances en Psicología Latinoamericana, 32(3), 433-446. doi: 10.12804/apl32.03.2014.09

Elliott, R., Fox, C. M., Beltyukova, S. A., Stone, G. E., Gunderson, J., \& Zhang, Xi. (2006). Deconstructing therapy outcome measurement with Rasch analysis: The SCL-90-R. Psychological Assessment, 18, 359-372. doi: 10.1037/10403590.18.4.359

Embretson, S. E., \& Reise, S. P. (2000). Item Response Theory for psychologists. New Jersey: Lawrence Erlbaum.

Hattie, J. (1985). Methodology review: Assessing unidimensionality of tests and ltems. Applied Psychological Measurement, 9(2), 139-164. Retrieved from https://conservancy.umn.edu/ bitstream/handle/11299/102073/v09n2p139.pdf?sequence $=1$

Hunsley, J., \& Meyer, G. (2003). The incremental validity of psychological testing and assessment: Conceptual, methodological, and statistical issues. Psychological 
Assessment, 15(4), 446-455. http://psycnet.apa.org/ doi/10.1037/1040-3590.15.4.446

Krueger, R. F., Derringer, J., Markon, K. E., Watson, D., \& Skodol, A. E. (2012). Initial construction of a maladaptive personality trait model and inventory for DSM-5. Psychological Medicine, 42(9), 1879-1890. doi: 10.1017/S0033291711002674

Linacre, J. M. (2009). Winsteps. Beaverton, Oregon: Winsteps.com.

Linacre, J. M., \& Wright, B. D. (1991). WINSTEPS-Rasch-Model computer programs. Chicago: MESA Press.

Meyer, G. J. (1999). Incremental Validity of the Rorschach Prognostic Rating Scale Over the MMPI Ego Strength Scale and IQ. Journal of Personality Assessment, 87, 223-225. https:// doi.org/10.1207/S15327752JPA7403 2

Millon, T. (2011). Disorders of Personality: introducing a DSM/ ICD spectrum from normal to abnormal. New Jersey: Wiley.

Morizot, J., Ainsworth, A. T., \& Reise, S. P. (2007). Toward modern psychometrics: Application of item response theory models in personality research. In. R. W. Robins, R. C. Fraley, \& R. F. Krueger (Eds.), Handbook or research methods in personality psychology (pp. 407-423). New York: Guilford.

Nunnally, J. C. (1978). Psychometric Theory. New York: McGrawHill.

Oliveira, S. E. S. (2016). Avaliação estrutural e dimensional da personalidade: estudos psicométricos e de aplicação clínica (Tese de Doutorado). Instituto de Psicologia, Universidade Federal do Rio Grande do Sul, Porto Alegre, RS, Brasil.

Oliveira, S. E. S., \& Krueger, R. F. (2015). Validity of the DSM-5 alternative personality disorder model in brazilian clinic and non-clinic samples. In Annual meeting of the society for research in psychopathology, 29. [Proceedings]. New Orleans: Society for Research in Psychopathology.

Paris, J. A. (2015). A concise guide to personality disorders. Washington: American Psychological Association.

Pasquali, L. (2007). Validade dos testes psicológicos: Será possível reencontrar o caminho? Psicologia: Teoria e Pesquisa, 23, 99-107. http://dx.doi.org/10.1590/S0102-37722007000500019
Primi, R., Carvalho, L. F., Miguel, F. K., \& Muniz, M. (2010). Resultado dos fatores da BFP por meio da Teoria de Resposta ao Item: interpretação referenciada nos itens. In C. H. S. S. Nunes, C. S. H. Hutz, \& M. F. O. Nunes (Orgs.), Bateria Fatorial de Personalidade: manual técnico (pp. 153-183). São Paulo: Casa do Psicólogo.

Skodol, A. E., Clark, L. A., Bender, D. S., Krueger, R. F., Morey, L. C., Verheul, R., Alarcon, R. D., ... Oldham, J. M. (2011). Proposed changes in personality and personality disorder assessment and diagnosis for DSM-5Part I: Description and rationale. Personality Disorders Theory Research and Treatment, 2(1), 4-22. doi: 10.1037/a0021891

Tavakol, M., \& Dennick, R. (2011). Making sense of Cronbach's alpha. International Journal of Medical Educational, 2, 53-55. doi: 10.5116/ijme.4dfb.8dfd

Thomas, K. M.; Yalch, M. M.; Krueger, R. F.; Wright, A. G. C.; Markon, K. E.; \& Hopwood, C. J. (2013). The Convergent Structure of DSM-5 Personality Trait Facets and Five-Factor Model Trait Domains. Assessment, 20(3), 308-311. doi: $10.1177 / 1073191112457589$.

Zuccolo, P. F., Corchs, F., \& Savoia, M. G. (2013). Psicopatologias e o conceito da Personalidade. In L. F. Carvalho \& R. Primi (Eds.), Perspectivas em psicologia dos transtornos da personalidade (pp. 8-23). São Paulo: Casa do Psicólogo. 